\title{
Invasive pulmonary aspergillosis in patients with chronic obstructive pulmonary disease
}

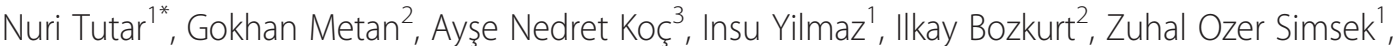 \\ Hakan Buyukoglan ${ }^{1}$, Asiye Kanbay ${ }^{1}$, Fatma Sema Oymak', Inci Gulmez ${ }^{1}$ and Ramazan Demir ${ }^{1}$
}

\begin{abstract}
Background: Invasive pulmonary aspergillosis (IPA) is an infection often occurring in neutropenic patients and has high mortality rates. In recent years, it has been reported that the incidence of IPA has also increased in patients with chronic obstructive pulmonary disease (COPD). The purpose of this study is to investigate the clinical and demographic characteristics and treatment responses of IPA in patients with COPD.

Methods: Seventy-one patients with a positive culture of Aspergillus from lower respiratory tract samples were examined retrospectively. Eleven (15.4\%) of these patients, affected with grade 3 or 4 COPD, had IPA.

Results: Aspergillus hyphae were detected in lung biopsy in three (27.3\%) out of 11 patients and defined as proven IPA; a pathological sample was not taken in the other eight (72.7\%) patients, and these were defined as probable IPA. Aspergillus isolates were identified as six cases of Aspergillusfumigatus and three of Aspergillusniger in nine patients, while two isolates were not identified at species level. While five patients required intensive care unit admission, four of them received mechanical ventilation. The most common finding on chest X-ray and computed tomography (CT) (respectively 63.6\%, 72.7\%) was infiltration. Amphotericin B was the initial drug of choice in all patients and five patients were discharged with oral voriconazole after amphotericin B therapy. Six patients (54.5\%) died before treatment was completed.

Conclusions: IPA should be taken into account in the differential diagnosis particularly in patients with severe and very severe COPD presenting with dyspnea exacerbation, poor clinical status, and a new pulmonary infiltrate under treatment with broad-spectrum antibiotics and steroids.
\end{abstract}

Keywords: Aspergillosis, Chronic obstructive pulmonary disease, COPD, Invasive pulmonary aspergillosis

\section{Background}

Invasive Pulmonary Aspergillosis (IPA) is frequently seen in patients with hematologic malignancy, allogenic bone marrow transplantation, the late stage of HIV infection, solid organ transplantation, and chronic granulomatosis [1-3]. In addition, the number of studies stating that IPA is increasing in cases with chronic obstructive pulmonary disease (COPD) has gradually risen in recent years [3-7].

In COPD patients ciliary activity impairment, immunosuppression due to alveolar macrophage and neutrophil inhibition in those treated with steroids and

\footnotetext{
* Correspondence: drnuritutar@gmail.com

'Department of Pulmonary Medicine, Erciyes University Faculty of Medicine, Kayseri 38039, Turkey

Full list of author information is available at the end of the article
}

also receiving broad-spectrum antibiotics, play a role in the development of IPA $[8,9]$. In a review, in which 1,941 patients followed up with the diagnosis of IPA were examined, COPD was detected in $1.3 \%$ of all cases [10]. In a study carried out in the years following this review, it was found that the frequency of IPA in COPD cases in 2007 had increased approximately more than twice with respect to the year 2000 in the same hospital [6]. This finding shows that the rate of IPA incidence in COPD patients is ever increasing. Based on this study carried out in Spain we planned to report our IPA cases with COPD. Hence, in the present study we aimed to investigate the clinical and demographic features of IPA in patients with COPD and also to examine the treatment outcomes and mortality rates.

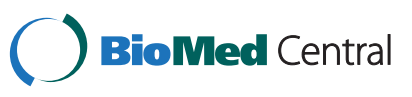




\section{Methods}

\section{Study population and case descriptions}

This retrospective study was carried out on patients who applied to Erciyes University Hospital, which has 1,300 in-patient bed availability. It was approved by the Ethics Review Board of Erciyes University (2013/269).

COPD diagnosis was established according to the Global Initiative for Chronic Obstructive Lung Disease (GOLD) criteria [11]. In patients with COPD, Bulpa criteria were used for IPA diagnosis [5]. Accordingly, the diagnosis of "proven IPA" was established by means of the presence of hyphae compatible with Aspergillus in the examination of specimens taken from a pulmonary lesion through pulmonary biopsy or needle aspiration, and by the isolation of Aspergillus species in culture from any upper respiratory tract (URT) sample together with evidence of associated tissue damage. The diagnosis of "probable IPA", it was established by the coexistence of host factors [patient with severe COPD according to GOLD (stage III or IV), usually treated with steroids, with recent exacerbation of dyspnoea, and suggestive chest imaging] and microbiological factors [Aspergillus isolation in LRT sample or two sequential positive serum galactomannan (GM) tests]. The diagnosis of "possible IPA" required host factors, but without microbiological proof, while "colonization" meant the patient was asymptomatic in spite of the isolation of Aspergillus in the lower respiratory tract samples.

In our study, the response to antifungal treatment was evaluated based upon the criteria determined by the European Organization for the Research and Treatment of Cancer (EORTC) and the Mycoses Study Group (MSG) [12]. Accordingly, a reduction of at least $25 \%$ in the diameter of radiological lesions, together with recovery in the findings of disease and disease-specific symptoms and the patient's being alive at the end of treatment were defined as treatment success. As for treatment failure, it was defined as follows: radiological stabilization (the $0-25 \%$ resolution of lesion diameter) together with a slight or no recovery in the findings of disease and coexistent symptoms despite the fact that the patient survived; the occurrence of disease in new areas together with the worsening of findings and symptoms of disease clinically; radiological deterioration of pre-existing lesion; continuous isolation of fungus species from the infected area; the patient's death within the 12 week-follow up period for whatever reason.

\section{Patient inclusion criteria and data collection}

In the present study we examined the data on the isolation of Aspergillus from LRT samples in our microbiology laboratory which were sent from the chest disease or infectious disease clinics between January 2006 and December 2011. The inclusion criteria were as follows: 1- the isolation of Aspergillus from LRT culture; 2- patients had
COPD in GOLD stage 3 (severe) or 4 (very severe); 3- patients had a history of steroid use (systemic or inhaled) in the last 3 weeks before admission or had a history of antibiotic use in the last 3 months before admission; 4- the isolation was not considered as colonization. The patients were diagnosed as "proven IPA" and "probable IPA". There was no case of "possible IPA" since only patients with a positive culture for Aspergillus were included in the study. The files, discharge reports and x-rays of all patients, which were registered in the hospital data processing system, were checked. Accordingly, we registered: demographic features, history of smoking, presence of other coexisting diseases, pulmonary function test results, history of drug use, clinical symptoms, results of laboratory tests, imaging findings, hospitalization periods, intensive care unit (ICU) admission, invasive mechanical ventilation support, and response to treatment.

\section{Microbiological procedures}

In the course of the study period, following the direct microscopic examination, all LRT specimens were cultured on Sabouraud dextrose agar (SDA) media with and without antibiotics. One of these was incubated at $37^{\circ} \mathrm{C}$ and the others in incubators at $25^{\circ} \mathrm{C}$ for 3 weeks and were evaluated as to whether isolation occurs 3 times in a week, or not. The identification of a colony presenting mould growth was carried out at species level according to macroscopic and microscopic morphology [13].

The galactomannan (GM) antigen level in serum was detected in all patients by Platelia Aspergillus Galactomannan EIA kits (Bio-Rad, Marnes-La-Coquette, France). The ratio of $\geq 0.5 \mathrm{ng} / \mathrm{mL}$ for $\mathrm{GM}$ was considered positive. A 1,3-beta D-Glucan level was detected by Fungitell kits (Associates of Cape Cod, East Falmouth, MA, USA) and a ratio of $>80 \mathrm{pg} / \mathrm{mL}$ was considered positive [2].

\section{Statistical method}

The frequency, percentage, mean, standard deviation, median and interquartile range values from descriptive statistics are presented. The SPSS 15.0 packaged software was used for the analysis of data.

\section{Results}

\section{Diagnostic and demographic characteristics of patients}

In 71 patients Aspergillus had been isolatedin LRT samples. Eleven out of them (15.4\%) had stage 3 or 4 COPD and these were the cases that applied to our hospital with complaints of dyspnea. As a result of lung biopsy in three cases $(27.3 \%)$ out of these 11 patients, hyphae compatible with Aspergillus were seen and identified as proven IPA; in the other eight cases $(72.7 \%)$, pathological specimens were not taken and these were identified as probable IPA. 
Six Aspergillus strains were defined as Aspergillus fumigatus and three as Aspergillus niger, while identification at species level in the other two strains was not made.

The mean age was $65.1 \pm 9.7$ years and 9 patients $(81.8 \%)$ were male. History of smoking was present in 8 cases $(72.7 \%)$. Ten patients $(90.9 \%)$ had been using a systemic steroid and $8(72.7 \%)$ an inhaler steroid over the last 3 weeks. History of antibiotic use was present in four patients over the last 3 months. The average diagnosis time was $13.8 \pm 3.8$ days after admission and the average hospitalization period was $24.7 \pm 13.9$ days. Five cases had ICU admission and four of them received invasive mechanical ventilation (Table 1).

\section{Symptoms, laboratory results and radiological findings}

The most frequent symptoms were dyspnea $(\mathrm{n}=11$, $100 \%)$ and cough $(\mathrm{n}=10,90.9 \%)$. Sputum, fever and hemoptysis were other recorded symptoms (Table 2). Moreover, GM was positive in nine patients (81.8\%). The median value for GM was $0.54 \mathrm{ng} / \mathrm{mL}$. Beta DGlucan was examined in five patients and was positive in three $(60 \%)$ of them.

The most frequent abnormal finding seen in chest $x$ ray was infiltration $(\mathrm{n}=7,63.6 \%)$. Cavitation, nodule, consolidation and pleural fluid came next in order of frequency. As for the thorax computed tomography

Table 1 Clinical and demographic characteristics of 11 COPD patients with IPA ${ }^{\mathrm{a}}$

\begin{tabular}{ll}
\hline Characteristics & \\
\hline \multicolumn{1}{l}{ Male } & $9(81.8)$ \\
$\quad$ Female & $2(18.2)$ \\
Mean age, years & $65.1 \pm 9.7$ \\
Smoking history & \\
$\quad$ Yes & $8(72.7)$ \\
$\quad>40$, pack years & $4(36.3)$ \\
Underlying disease & \\
$\quad$ Diabetes mellitus & $1(9.0)$ \\
$\quad$ Cardiovascular disease & $3(27.2)$ \\
Steroid treatment & \\
$\quad$ Inhaled & \\
$\quad$ Systemic use & $8(72.7)$ \\
Recent use of antibiotics & \\
Time to diagnosis, days & $10(90.9)$ \\
Hospitalization period, days & $4(36.3)$ \\
ICU admission & $13.8 \pm 3.8$ \\
Mechanical ventilation & $24.7 \pm 13.9$ \\
Death & $5(45.4)$ \\
\hline
\end{tabular}

${ }^{\mathrm{a}}$ Data are presented as number (\%) or average \pm standard deviation. ${ }^{b}$ Within three weeks before applying, 'Within three months before applying.
Table 2 Symptoms, laboratory and radiological findings of 11 COPD patients with IPA

\begin{tabular}{ll}
\hline Symptom, $\mathbf{n}(\%)$ & \\
\hline Fever & $5(45.4)$ \\
Cough & $10(90.9)$ \\
Dyspnea & $11(100)$ \\
Sputum & $7(63.6)$ \\
Hemoptysis & $2(18.1)$ \\
Laboratory, average $\pm \mathrm{SD}$ or median (IQR) & \\
White blood cell, $10^{3} / \mathrm{mL}$ & $13.5 \pm 5.2$ \\
Hemoglobin, $\mathrm{g} / \mathrm{dL}$ & $12.0 \pm 2.8$ \\
Thrombocyte, $10^{3} / \mathrm{mL}$ & $352.1 \pm 175.1$ \\
Sedimentation, $\mathrm{mm} / \mathrm{hour}$ & $88 \pm 25$ \\
CRP, mg/L & $117 \pm 50$ \\
Galactomannan, $\mathrm{ng} / \mathrm{mL}$ & $0.54(0.17-9.16)$
\end{tabular}

Radiological findings, $\mathrm{n}(\%)$

Chest X-ray

Infiltration 7 (63.6)

Cavity $3(27.2)$

Nodule $3(27.2)$

Pleural fluid $\quad 2(18.1)$

Consolidation 2(18.1)

Worsening radiological findings $^{\mathrm{a}} \quad 7$ (63.6)

Computed tomography

Infiltration $\quad 8$ (72.7)

Nodule 4 (36.3)

Consolidation 3 (27.2)

Cavitation 3 (27.2)

Pleural fluid 2 (18.1)

$\mathrm{IQR}$, Interquartile range.

${ }^{a} \mathrm{New}$ images of infection appeared or old lesions worsened compared to previous chest radiographs.

(CT) findings, again infiltration was frequently encountered $(n=8,72.7 \%)$. Nodule, consolidation, cavity and pleural fluid was next in order of frequency (Table 2). Progress in radiological findings for infection before antifungal treatment was detected in seven cases $(63.6 \%)$.

\section{Antifungal treatment and results}

Diagnostic procedures, treatment and results for all patients are shown in Table 3. In terms of treatment, all cases received amphotericin B [7 (63.6\%) amphotericin B deoxycholate, 4 (36.4\%) liposomal amphotericin B] for initial treatment and $5(45.4 \%)$ patients were discharged with oral voriconazole. Six (54.5\%) patients died before the completion of treatment and were considered as "treatment failure". In 5 patients (45.4\%), 
Table 3 Diagnosis, antifungal therapy, and outcomes in 11 COPD patients with IPA

\begin{tabular}{|c|c|c|c|c|c|c|c|c|c|c|}
\hline & Diagnosis & Risk factor ${ }^{a}$ & Chest x-ray & Thorax CT & Type of specimen & Isolation type & Antifungal treatment & $\begin{array}{l}\text { GM value and } \\
\text { control }(\mathrm{ng} / \mathrm{mL})\end{array}$ & $\begin{array}{l}\text { Beta D- Glucan } \\
(\mathrm{pg} / \mathrm{mL})\end{array}$ & Death \\
\hline 1 & Probable & Steroid & $\begin{array}{l}\text { Infiltration, } \\
\text { cavitation }\end{array}$ & Infiltration, cavity & Sputum, pleural fluid & A. niger & LAMB & $3.79 \rightarrow 0.24$ & none & Yes \\
\hline 2 & Probable & Steroid & Infiltration & Infiltration & Bronchial lavage & A. fumigatus & LAMB & $0.53 \rightarrow$ none & none & Yes \\
\hline 3 & Probable & Steroid & Cavitation & Cavity & Sputum & $\begin{array}{l}\text { Aspergillus } \\
\text { species }\end{array}$ & AMB & $3.79 \rightarrow 2.33$ & none & Yes \\
\hline 4 & Probable & $\begin{array}{l}\text { Steroid and } \\
\text { antibiotic }\end{array}$ & Infiltration & $\begin{array}{l}\text { Infiltration, } \\
\text { consolidation }\end{array}$ & $\begin{array}{l}\text { Sputum and bronchial } \\
\text { lavage }\end{array}$ & $\begin{array}{l}\text { Aspergillus } \\
\text { species }\end{array}$ & AMB & $9.16 \rightarrow$ none & none & Yes \\
\hline 5 & Probable & Steroid & Consolidation & Consolidation & Bronchial lavage & A. niger & AMB & $5.48 \rightarrow 4.38$ & none & Yes \\
\hline 6 & Probable & Steroid & Cavitation, nodule & $\begin{array}{l}\text { Infiltration, cavity, } \\
\text { nodule }\end{array}$ & Sputum & A. fumigatus & AMB & $0.22 \rightarrow$ none & $>523$ & Yes \\
\hline 7 & Proven $^{\mathrm{b}}$ & $\begin{array}{l}\text { Steroid and } \\
\text { antibiotic }\end{array}$ & $\begin{array}{l}\text { Consolidation, } \\
\text { nodule }\end{array}$ & Consolidation, nodule & Sputum & A. fumigatus & $\begin{array}{l}\text { AMB, then } \\
\text { voriconazole }\end{array}$ & $0.54 \rightarrow 0.33$ & 59 & No \\
\hline 8 & Proven $^{\mathrm{b}}$ & Antibiotic & Infiltration & Infiltration, nodule & Bronchial lavage & A. fumigatus & $\begin{array}{l}\text { AMB, then } \\
\text { voriconazole }\end{array}$ & $0.60 \rightarrow 0.30$ & none & No \\
\hline 9 & Probable & Steroid & Infiltration & Infiltration & Bronchial lavage & A. fumigatus & $\begin{array}{l}\mathrm{AMB} \text {, then } \\
\text { voriconazole }\end{array}$ & $0.50 \rightarrow 0.16$ & 51 & No \\
\hline 10 & Probable & Steroid & Infiltration, nodule & Infiltration, nodule & Sputum & A. niger & $\begin{array}{l}\text { LAMB, then } \\
\text { voriconazole }\end{array}$ & $0.17 \rightarrow$ none & 90 & No \\
\hline 11 & Proven $^{\mathrm{b}}$ & $\begin{array}{l}\text { Steroid and } \\
\text { antibiotic }\end{array}$ & Infiltration & Infiltration & Transbronchial biopsy & A. fumigatus & $\begin{array}{l}\text { LAMB, then } \\
\text { voriconazole }\end{array}$ & $0.39 \rightarrow$ none & $>523$ & No \\
\hline
\end{tabular}

aThe term Steroid includes only systemic corticosteroid treatment.

${ }^{\mathrm{b}}$ Hyphae were seen in the pathological examination of biopsy material.

AMB, Amphotericin B deoxycholate; IPA, Invasive pulmonary aspergillosis; LAMB, Liposomal amphotericin B. 
clinical and radiological improvement after antifungal treatment was followed up and these cases were acknowledged as "treatment success". In those patients in whom treatment success was observed, the average duration of treatment was 137.2 days; instead it was 15.8 days in the patients who died.

\section{Discussion}

In the present study, the diagnosis and treatment features of 11 COPD cases, who had IPA but no other immunosupressive diseases, were analyzed. In recent years, it has been shown that corticosteroid use plays a significant role in terms of increasing the rate of IPA incidence in COPD cases [5,6]. In one retrospective study, it was shown that steroid use of over $700 \mathrm{mg}$ in total within the last three months in COPD patients increased the risk of IPA [6]. Also, it has been stated by some authors that inhaled steroids are a risk factor for IPA [14]. While $72.7 \%$ of cases in this study had used an inhaled steroid, 10 cases $(90.9 \%)$ had used a systemic steroid within the last 3 weeks.

Another risk factor charged with the development of IPA in COPD patients is broad-spectrum antibiotic treatment. In one study, it was pointed out that treatment with a wide range of broad-spectrum antibiotics used before hospitalization in COPD cases was associated with the development of IPA and another study showed that using three or more antibiotics for 10 days was a risk factor for IPA development in patients with COPD $[15,16]$. In the present study, similar to other reports, four cases had used antibiotics in the last 3 months and a history of antibiotic use was the only risk factor in one case that did not receive systemic steroid treatment.

Since underlying disease may mask the findings of Aspergillus lung invasion, clinical symptoms and radiological findings are nonspecific in cases with COPD [6]. In COPD patients where IPA had developed, dyspnea was reported as the most frequent symptom and cough, wheezing, increase in sputum amount and fever may also be seen [16]. The most frequent radiologic finding was infiltration [6,7] that is non specific and may correspond to a COPD exacerbation caused by bacterial pulmonary infection, frequently encountered especially in chest disease clinics. For this reason, patients are frequently diagnosed as affected with IPA following their hospitalization. In our study, we were able to diagnose IPA in an average of 13.8 days after hospitalization. This also shows that an early screening test for IPA should be performed. In addition, the isolation of Aspergillus strains in culture and no regression in radiological and clinical findings with appropriate antibiotic treatment are the most important findings which suggest IPA. In this study, similar to other reports, the dyspnea was reported in all cases and the chest $\mathrm{x}$-rays of seven cases at follow up showed a progression of findings compared to the chest $x$-ray on hospital admission.

In studies carried out on patients with hematologic malignancy from our country, GM antigen test sensitivity was found as $56-61 \%$ and its specificity as $21-84 \%$ $[17,18]$. However, in studies carried out on COPD cases in different centers, GM antigen test sensitivity in the diagnosis of IPA was stated as $46.2-80 \%$ and specificity as $83.3-94.1 \%[16,19,20]$. In addition, it has been indicated that GM positivity in COPD patients with IPA development in intensive care and the isolation of Aspergillus species in respiratory samples may be significant in terms of mortality [3]. As for our study, the GM value was found to be positive in $9(81.8 \%)$ cases, and 5 of them $(55.5 \%)$ died. This gives further support to the belief that GM positivity in COPD cases with the development of IPA is a significant parameter to be considered in terms of mortality. Moreover, it is conceivable that a GM value positive in the diagnostic period will become negative in cases responding to treatment [21]. In 2 of our 7 cases where the GM test was repeated after they received antifungal treatment for at least one week, it was found that GM value was still positive, in fact treatment failed in both patients and they died (Table 3). While 1,3-beta-D-glucan was found to be negative in two cases for whom the GM value was positive, it was found positive in three IPA cases with negative GM test. In a study carried out recently, the sensitivity of the 1,3beta-D-glucan test in the diagnosis of IPA was reported as $66 \%$ and its specificity as $75.6 \%$ [22]. Especially in patients from whom a bronchoscopic sample was not taken, applying both serologic methods may increase diagnostic sensitivity, although prospective systematic studies analyzing this application in patients with COPD are needed.

Even though amphotericin B has been used as the first-line antifungal agent in the treatment of IPA for many years, in a comparative study carried out in 2002 voriconazole was more successful than amphotericin $B$ as the primary mode of invasive aspergillosis treatment [23]. Saito et al. also observed a good response as high as $60.6 \%$ with voriconazole in patients with chronic pulmonary aspergillosis [24]. In a recent study, Chu et al. reported 108 invasive fungal infections treated with voriconazole in whom 83 patients $(76.8 \%)$ were IPA [25]. Although the authors, in patients with proven and probable invasive fungal disease, did not find a significant relationship between therapeutic voriconazole levels and achievement of complete or partial response at 12 weeks, radiologic response was noted in $55.2 \%$ of patients with invasive pulmonary aspergillosis. In addition, they found complete or partial 
response at 6 weeks with initial subtherapeuticvoriconazole levels in seven patients all affected with invasive pulmonary aspergillosis. In the present study partial response was achieved in $45.4 \%$ of patients and all received voriconazole after initial amphotericin B therapy. This was due to the fact that treatment in living cases was continued with the use of voriconazole by virtue of its oral form being available.

In the studies of different centers, the mortality rate of IPA in COPD cases was reported to be between $43.3 \%$ and $95 \%[5-7,16,26]$. In our study, the mortality rate was $54.5 \%$, however, to define the excess cause of mortality is difficult in this patient group since they had a very limited lung function based on the stage of COPD.

\section{Conclusions}

In conclusion, we believe that "proven" or "probable" IPA should be taken into account in differential diagnosis, particularly in patients with severe and very severe COPD presenting with dyspnea exacerbation, poor clinical status, and a new pulmonary infiltrate on chest radiograph under treatment with broad-spectrum antibiotics and steroids. The presents study shows that the LRT culture for Aspergillus, serum GM test and chest imaging ( $\mathrm{x}$-ray and $\mathrm{CT}$ ) can be useful for the early differential diagnosis of IPA, and voriconazole should be given for the treatment of such patients.

\section{Availability of supporting data}

The data set supporting the results of this article is included within the article.

\section{Competing interests}

The authors declare that they have no competing interests.

\section{Author details}

${ }^{1}$ Department of Pulmonary Medicine, Erciyes University Faculty of Medicine, Kayseri 38039, Turkey. ${ }^{2}$ Department of Infectious Diseases and Clinical Microbiology, Erciyes University Faculty of Medicine, Kayseri, Turkey.

${ }^{3}$ Department of Microbiology, Kayseri, Turkey.

Received: 1 April 2013 Accepted: 24 July 2013

Published: 4 September 2013

\section{References}

1. Chakrabarti A, Chatterjee SS, Das A, Shivaprakash MR: Invasive aspergillosis in developing countries. Med Mycol 2011, 49(Suppl 1):S35-S47.

2. Marchetti $O$, Lamoth F, Mikulska M, Viscoli C, Verweij P, Bretagne S, European Conference on Infections in Leukemia (ECIL) Laboratory Working Groups: ECIL recommendations for the use of biological markers for the diagnosis of invasive fungal diseases. Bone Marrow Transplant 2012, 47:846-854.

3. Meersseman W, Vandecasteele SJ, Wilmer A, Verbeken E, Peetermans WE, Van Wijngaerden E: Invasive aspergillosis in critically ill patients without malignancy. Am J Respir Crit Care Med 2004, 170:621-625.

4. Ribaud P, Chastang C, Latgé JP, Baffroy-Lafitte L, Parquet N, Devergie A, Espérou $H$, Sélimi F, Rocha $V$, Espérou $H$, Sélimi F, Rocha $V$, Derouin F, Socié G, Gluckman E: Survival and prognostic factors of invasive aspergillosis after allogenic bone marrow transplantation. Clin Infect Dis 1999, 28:322-330.
5. Bulpa PA, Dive AM, Sibille $Y$ : Invasive pulmonary aspergillosis in patients with chronic obstructive pulmonary disease. Eur Respir J 2007, 30:782-800

6. Guinea J, Torres-Narbona M, Gijón P, Muñoz P, Pozo F, Peláez T, de Miguel J, Bouza E: Pulmonary aspergillosis in patients with chronic obstructive pulmonary disease: incidence, risk factors, and outcome. Clin Microbiol Infect 2010, 16:870-877.

7. Xu H, Li L, Huang WJ, Wang LX, Li WF, Yuan WF: Invasive pulmonary aspergillosis in patients with chronic obstructive pulmonary disease: a case control study from China. Clin Microbiol Infect 2012, 18:403-408.

8. Philippe B, Ibrahim-Granet O, Prévost MC, Gougerot-Pocidalo MA, Sanchez Perez M, van der Meeren A, Latgé JP: Killing of Aspergillusfumigatus by alveolar macrophages is mediated by reactive oxidant intermediates. Infect Immun 2003, 71:3034-3042.

9. Roilides E, Uhlig K, Venzon D, Pizzo PA, Walsh TJ: Enhancement of oxidative response and damage caused by human neutrophils to Aspergillusfumigatus hyphae by granulocyte colony-stimulating factor and gamma Interferon. Infect Immun 1993, 61:1185-1193.

10. Lin SJ, Schranz J, Teutsch SM: Aspergillosis case-fatality rate: Systematic review of the literature. Clin Infect Dis 2001, 32:358-366.

11. Rabe KF, Hurd S, Anzueto A, Barnes PJ, Buist SA, Calverley P, Fukuchi Y, Jenkins C, Rodriguez-Roisin R, van Weel C, Zielinski J, Global Initiative for Chronic Obstructive Lung Disease: Global strategy for the diagnosis, management, and prevention of chronic obstructive pulmonary disease: GOLD executive summary. Am J Respir Crit Care Med 2007, 176:532-535.

12. Segal BH, Herbrecht R, Stevens DA, Ostrosky-Zeichner L, Sobel J, Viscoli C, Walsh TJ, Maertens J, Patterson TF, Perfect JR, Dupont B, Wingard JR, Calandra T, Kauffman CA, Graybill JR, Baden LR, Pappas PG, Bennett JE, Kontoyiannis DP, Cordonnier C, Viviani MA, Bille J, Almyroudis NG, Wheat LJ, Graninger W, Bow EJ, Holland SM, Kullberg BJ, Dismukes WE, De Pauw BE: Defining responses to therapy and study outcomes in clinical trials of invasive fungal diseases: Mycoses Study Group and European Organization for Research and Treatment of Cancer consensus criteria. Clin Infect Dis 2008, 47:674-683.

13. Verweij PE, Brandt ME: Aspergillus, Fusarium, and other opportunistic moniliaceous fungi. In Manual of Clinical Microbiology, Volume 2. 9th edition. Edited by Murray PR, Baron EJ, Jorgensen JH, Landry ML, Pfaller MA. Washington: ASM Press; 2007:1802-1838.

14. Leav BA, Fanburg B, Hadley S: Invasive pulmonary aspergillosis associated with high-dose inhaled fluticasone. N Engl J Med 2000, 343:586.

15. Muquim A, Dial S, Menzies D: Invasive aspergillosis in patients with chronic obstructive pulmonary diseases. Can Respir J 2005, 12:199-204.

16. He H, Ding L, Li F, Zhan Q: Clinical features of invasive bronchialpulmonary aspergillosis in critically ill patients with chronic obstructive respiratory diseases: a prospective study. Crit Care 2011, 15:R5.

17. Metan G, Koç AN, Atalay A, Kaynar LG, Ozturk A, Alp E, Eser B: The peformance of galactomannan antigen assay in the diagnosis of invasive pulmonary aspergillosis at different cutoff values. Mycoses 2011 54(Suppl 2):80-81.

18. Tanriover MD, Ascioglu S, Altun B, Uzun O: Galactomannan on the stage: prospective evaluation of the applicability in routine practice and surveillance. Mycoses 2010, 53:16-25.

19. He H, Ding L, Chang S, Li F, Zhan Q: Value of consecutive galactomannan determinations for the diagnosis and prognosis of invasive pulmonary aspergillosis in critically ill chronic obstructive pulmonary disease. Med Mycol 2011, 49:345-351.

20. Gao X, Chen L, Hu G, Mei H: Invasive pulmonary aspergillosis in acute exacerbation of chronic obstructive pulmonary disease and the diagnostic value of combined serological tests. Ann Saudi Med 2010 30:193-197

21. Koo S, Bryar JM, Baden LR, Marty FM: Prognostic features of galactomannanantigenemia in galactomannan-positive invasive aspergillosis. J Clin Microbiol 2010, 48:1255-1260.

22. Metan G, Koç AN, Atalay A, Kaynar LG, Ozturk A, Alp E, Eser B: What should be the optimal cut-off of serum 1,3-B-D-glucan for the detection of invasive pulmonary aspergillosis in patients with haematological malignancies? Scand J Infect Dis 2012, 44:330-336

23. Herbrecht R, Denning DW, Patterson TF, Bennett JE, Greene RE, Oestmann JW, Kern WW, Marr KA, Ribaud P, Lortholary O, Sylvester R, Rubin RH, Wingard JR, Stark P, Durand C, Caillot D, Thiel E, Chandrasekar PH, Hodges MR, Schlamm HT, Troke PF, de Pauw B, Invasive Fungal Infections Group of the European Organisation for Research and Treatment of Cancer and the 
Global Aspergillus Study Group: Voriconazole versus amphotericin B for primary therapy of invasive aspergillosis. N Engl J Med 2002, 347:408-415.

24. Saito T, Fujiuchi S, Tao Y, Sasaki Y, Ogawa K, Suzuki K, Tada A, Kuba M, Kato T, Kawabata M, Kurashima A, Sakatani M, NHO Pulmonary Fungosis Research Group: Efficacy and safety of voriconazole in the treatment of chronic pulmonary aspergillosis: experience in Japan. Infection 2012, 40:661-667.

25. Chu HY, Jain R, Xie H, Pottinger P, Fredricks DN: Voriconazole therapeutic drug monitoring: retrospective cohort study of the relationship to clinical outcomes and adverse events. BMC Infect Dis 2013, 13:105.

26. Blot SI, Taccone FS, van den Abeele AM, Bulpa P, Meersseman W, Brusselaers N, Dimopoulos G, Paiva JA, Misset B, Rello J, Vandewoude K, Vogelaers D, AsplCU Study Investigators: A clinical algorithm to diagnose invasive pulmonary aspergillosis in critically ill patients. Am J Respir Crit Care Med 2012, 186:56-64.

doi:10.1186/2049-6958-8-59

Cite this article as: Tutar et al:: Invasive pulmonary aspergillosis in patients with chronic obstructive pulmonary disease. Multidisciplinary Respiratory Medicine 2013 8:59.

\section{Submit your next manuscript to BioMed Central and take full advantage of:}

- Convenient online submission

- Thorough peer review

- No space constraints or color figure charges

- Immediate publication on acceptance

- Inclusion in PubMed, CAS, Scopus and Google Scholar

- Research which is freely available for redistribution 